\title{
Improved Subcell Model for the Prediction of Braided Composite Response
}

Christopher R. Cater and Xinran Xiao

Michigan State University, East Lansing, Michigan

Robert K. Goldberg and Lee W. Kohlman

Glenn Research Center, Cleveland, Ohio 


\section{NASA STI Program . . . in Profile}

Since its founding, NASA has been dedicated to the advancement of aeronautics and space science. The NASA Scientific and Technical Information (STI) program plays a key part in helping NASA maintain this important role.

The NASA STI Program operates under the auspices of the Agency Chief Information Officer. It collects, organizes, provides for archiving, and disseminates NASA's STI. The NASA STI program provides access to the NASA Aeronautics and Space Database and its public interface, the NASA Technical Reports Server, thus providing one of the largest collections of aeronautical and space science STI in the world. Results are published in both non-NASA channels and by NASA in the NASA STI Report Series, which includes the following report types:

- TECHNICAL PUBLICATION. Reports of completed research or a major significant phase of research that present the results of NASA programs and include extensive data or theoretical analysis. Includes compilations of significant scientific and technical data and information deemed to be of continuing reference value. NASA counterpart of peer-reviewed formal professional papers but has less stringent limitations on manuscript length and extent of graphic presentations.

- TECHNICAL MEMORANDUM. Scientific and technical findings that are preliminary or of specialized interest, e.g., quick release reports, working papers, and bibliographies that contain minimal annotation. Does not contain extensive analysis.

- CONTRACTOR REPORT. Scientific and technical findings by NASA-sponsored contractors and grantees.
- CONFERENCE PUBLICATION. Collected papers from scientific and technical conferences, symposia, seminars, or other meetings sponsored or cosponsored by NASA.

- SPECIAL PUBLICATION. Scientific, technical, or historical information from NASA programs, projects, and missions, often concerned with subjects having substantial public interest.

- TECHNICAL TRANSLATION. Englishlanguage translations of foreign scientific and technical material pertinent to NASA's mission.

Specialized services also include creating custom thesauri, building customized databases, organizing and publishing research results.

For more information about the NASA STI program, see the following:

- Access the NASA STI program home page at http://www.sti.nasa.gov

- E-mail your question to help@sti.nasa.gov

- Fax your question to the NASA STI Information Desk at 443-757-5803

- Phone the NASA STI Information Desk at 443-757-5802

- Write to: STI Information Desk NASA Center for AeroSpace Information 7115 Standard Drive Hanover, MD 21076-1320 
NASA/TM-2013-217875

AIAA-2013-1618

\section{Improved Subcell Model for the Prediction of Braided Composite Response}

Christopher R. Cater and Xinran Xiao

Michigan State University, East Lansing, Michigan

Robert K. Goldberg and Lee W. Kohlman

Glenn Research Center, Cleveland, Ohio

Prepared for the

The 54th Structures, Structural Dynamics, and Materials Conference (SDM) cosponsored by AIAA, ASME, ASCE, AHS, and ASC

Boston, Massachusetts, April 8-11, 2013

National Aeronautics and

Space Administration

Glenn Research Center

Cleveland, Ohio 44135 


\section{Acknowledgments}

The authors would like to thank the NASA Lewis Educational and Research Collaborative Internship Program for its support, as well as colleagues for their assistance and insight. These include Dr. Gary Roberts and Dr. Kelly Carney of NASA Glenn Research Center (GRC). The work was funded by the VSST project of the Aviation Safety Program.

Trade names and trademarks are used in this report for identification only. Their usage does not constitute an official endorsement, either expressed or implied, by the National Aeronautics and Space Administration.

Level of Review: This material has been technically reviewed by technical management.

Available from

NASA Center for Aerospace Information 7115 Standard Drive

Hanover, MD 21076-1320
National Technical Information Service 5301 Shawnee Road Alexandria, VA 22312

Available electronically at http://www.sti.nasa.gov 


\title{
Improved Subcell Model for the Prediction of Braided Composite Response
}

\author{
Christopher R. Cater and Xinran Xiao \\ Michigan State University \\ East Lansing, Michigan 48823 \\ Robert K. Goldberg and Lee W. Kohlman \\ National Aeronautics and Space Administration \\ Glenn Research Center \\ Cleveland, Ohio 44135
}

\begin{abstract}
In this work, the modeling of triaxially braided composites was explored through a semi-analytical discretization. Four unique subcells, each approximated by a "mosaic" stacking of unidirectional composite plies, were modeled through the use of layered-shell elements within the explicit finite element code LS-DYNA. Two subcell discretizations were investigated: a model explicitly capturing pure matrix regions, and a novel model which absorbed pure matrix pockets into neighboring tow plies. The in-plane stiffness properties of both models, computed using bottom-up micromechanics, correlated well to experimental data. The absorbed matrix model, however, was found to best capture out-of-plane flexural properties by comparing numerical simulations of the out-of-plane displacements from single-ply tension tests to experimental full field data. This strong correlation of out-of-plane characteristics supports the current modeling approach as a viable candidate for future work involving impact simulations.
\end{abstract}

\subsection{Introduction}

Triaxially braided composites have been implemented into fan containment systems for jet engines due to the high-specific stiffness and strength of fiber-reinforced polymer matrix systems and the improved impact damage tolerance and delamination resistance of braided architectures. These types of composites, however, present significant disadvantages for numerical modeling and simulation. First, previous impact studies have shown architectural dependence on damage evolution and damage patterns during a ballistic impact event (Ref. 1). Consequently, an appropriate modeling strategy must account for the nonhomogeneity present at the mesoscale: the scale of the braided pattern. Second, standardized coupon testing used for metals and simpler composite architectures have been shown to be relatively ineffective for determining braided composite strength properties (Ref. 2). Thus, accurate strength properties required for standard finite element composite damage models are currently unavailable. Additionally, the modeling scheme must be computationally efficient in order to be suitable for modeling of dynamic events such as a fan-blade-out event. The current work presented proposes to improve on already developed semi-analytical methods utilizing layered-shell elements and existing composite material models within the explicit finite element code LS-DYNA (Ref. 3). The overall goal is to develop a modeling algorithm which can best capture mechanisms of deformation and damage unique to the braided reinforcement architecture.

Analytical methods for determining the elastic properties of braided composites utilizing micromechanics were first developed as an extension of previous literature on woven composites. These typically involved first identifying the repeating unit cell, RUC, of the braided mesostructure. Ishikawa and Chou developed mosaic, fiber undulation and bridging models, modifying classical laminate theory to account for fiber undulations (Refs. 4 and 5). Naik and Shembekar (Refs. 6 and 7) extended the onedimensional mosaic model into two dimensions, whereas Yang et al. (Ref. 8) improved on accounting for fiber undulation in a fiber inclination model. Branch et al. (Ref. 9) extended a fiber inclination model into three dimensions. Redman and Douglas (Ref. 10) implemented the mosaic model using the rule of 
mixtures and classical lamination plate theory (CLPT). More advanced discretizations of the RUC were developed by Ivanov and Tabei (Refs. 11 to 13), splitting it into four unique subcells. Huang (Refs. 14 to 16) developed a micromechanical model modeling individual subcells as regions of two yarns and two pure matrix regions and treating each as a unidirectional (UD) composite. Quek et al. (Ref. 17) developed an analytical model which consisted of one axial tow, two braider tows, and one matrix layer. Concentric cylinder modeling was used to determine the homogeneous properties of the RUC. Carey et al. (Ref. 18) divided the braided RUC into 13 distinct regions and utilized a volume weighted stiffness matrix to homogenize the properties of the RUC. It was noted in Masters et al. (Ref. 19) that simple analytical laminate models performed well for stiffness predictions, whereas Falzon (Ref. 20) noted that these representations were unable to accurately capture out-of-plane properties.

There are three classifications of numerical methods for predicting the response of triaxially braided composites. The first includes those which model the RUC explicitly through finite element (FE) models (Refs. 21 to 23). In these approaches, the explicit models are used to determine the effective properties (stiffness/strength) of the RUC for use in structural simulations. A review of these types of numerical methods can be found in (Ref. 24). A second branch utilizes multiscale methodologies to link the explicit FE representation of the RUC with homogenized elements on the structural level (Ref. 25). Lastly, a semi-analytical method was developed (Refs. 26 and 27) based on a braiding-through-the-thickness method introduced by Cheng and Binienda (Ref. 28) utilizing layered shell elements, subcell discretizations, and the inherent CLPT implementation available in FE packages. Xiao et al. (Ref. 29) utilized a similar layered shell methodology with a unique subcell discretization.

In the current work, the semi-analytical methodology is utilized and builds upon limitations in the previous models by Cheng and Binienda (Ref. 28) and Xiao et al. (Ref. 29). Section 2.0 will discuss the general methodology in the semi-analytical approach using subcell models and introduce the novel absorbed matrix model. Section 3.0 will cover the numerical implementation of the modeling procedure and Section 4.0 will verify the in-plane elastic properties of the subcell models. Finally, the efficacy of the absorbed matrix model will be demonstrated with novel simulations of single-ply transverse tension tests in Section 5.0.

\subsection{Subcell Modeling}

\section{$2.1 \quad$ Previous Works}

The material system of interest is a $\left[0^{\circ} / 60^{\circ} /-60^{\circ}\right]$ triaxially braided composite made of $24 \mathrm{k}$ carbon fiber bundles in the $0^{\circ}$ tow direction and $12 \mathrm{k}$ carbon fiber bundles in the $\pm 60^{\circ}$ braider directions. Braider geometries were formed by A\&P Technologies and RTM molding was done by North Coast Composites (Refs. 1, 2, and 30). Fiber and matrix constituent sources and properties are provided in Section 3.1. A typical RUC, the smallest characteristic volume capturing the effective properties of this braided composite, is shown in Figure 1(a). The unit cell can be decomposed into 4 subcells as outlined in Figure 1(b). This partitioning corresponds to the existence of regions where axial $\left(0^{\circ}\right)$ and braider $\left(+60^{\circ} /-60^{\circ}\right)$ tows are both present and regions where only the braider tows are present. Figure 1(b) only displays the fiber tows in the braided composite and not the pure matrix regions which exist between and around fiber tows. The boundary of subcells A and $\mathrm{C}$ are drawn to lie at the edges of axial fiber tows. The individual subcells can be subsequently discretized in a "mosaic" model of UD composite plies to capture the orientation and response of the fiber tows within the triaxial braid. Previous subcell modeling (Refs. 26 to 28, and 30) developed in collaboration with the NASA Glenn Research Center (GRC) and the University of Akron, shown in Figure 2(a), utilized subcells containing two unique UD plies: one containing the axial tow, and another containing the braider tow and surrounding matrix material. The two UD plies were assigned unique fiber volume fractions. These volume fractions were determined by matching global fiber volume fractions and assuming 80 percent fiber volume fraction in the $0^{\circ}$ plies. The fiber volume fraction of the axial tows in this braided composite have been previously assumed to be 80 percent (Ref. 26). 
(a)

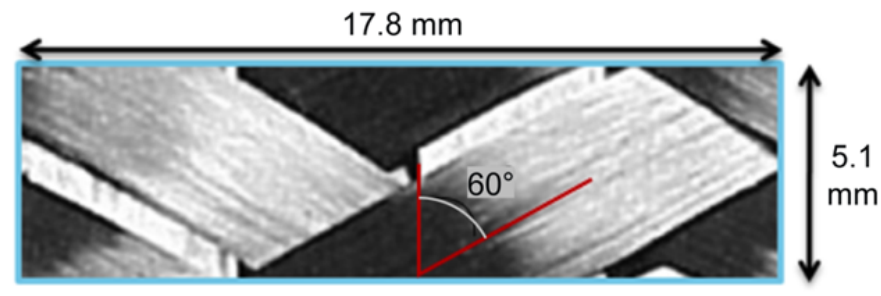

(b)

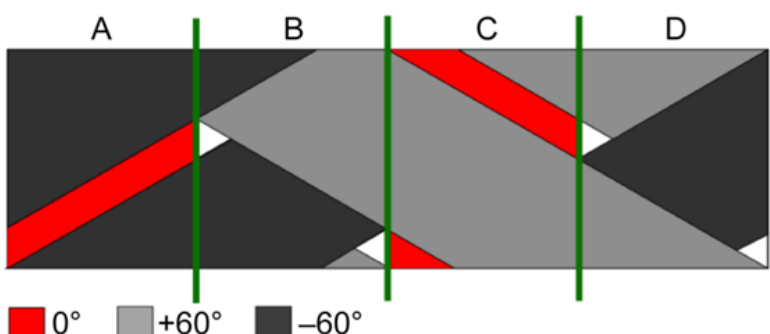

Figure 1.-(a) Unit cell of the braided composite. (b) The subcell segments with braid angles shown.

(a)

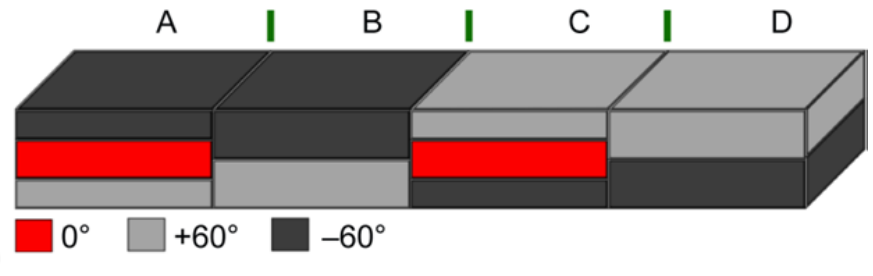

(b)

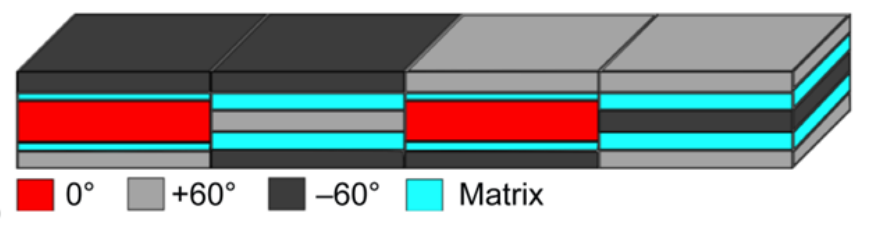

Figure 2.-(a) Subcell UD discretization of previous layered shell models developed at GRC and $U$ of Akron (Refs. 26 to 28, 30).

(b) The subcell model developed by Xiao et al. (Ref. 29).

There were two limitations to these previous models which are addressed in this work. First, the latest revision of the semi-analytical model homogenized each subcell through the thickness, resulting in a single layer for each subcell (Ref. 27). Although the model was still able to capture in-plane stiffness and strength properties of the braided composite, unique flexural properties of individual subcells were lost, such as the unique tension-twist coupling of the unsymmetric subcell laminate documented by Kohlman (Ref. 2). Secondly, the fiber volume fraction of the $\pm 60^{\circ}$ UD plies in the model in Figure 2(a) were determined by meeting the global composite fiber volume fraction, but did not reflect the actual fiber volume fraction contained in the given subcells.

The subcell model developed by Xiao et al. (Ref. 29) overcame these limitations by retaining the layered shell formulation for each individual subcell as well as developing a simple straight line model for determining ply thicknesses and UD fiber volume fractions. Xiao et al. also modeled fiber tows as unique UD plies, where the fiber volume fraction of each ply was identical to that of the fiber tow ( $\sim 80$ percent) and pure matrix pockets were modeled explicitly using the resin properties. Figure 2(b) displays the discretization, which hereon is referred to as the pure matrix model. Another significant advantage to the 


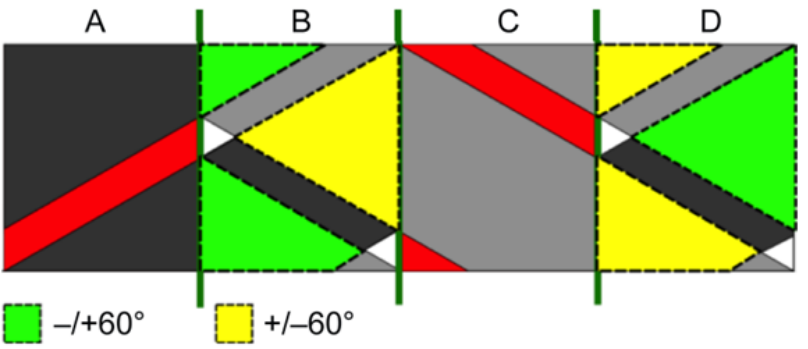

Figure 3.-Schematic highlighting the equivalence of $+/-60^{\circ}$ and $-1+60^{\circ}$ tows in subcells $B$ and $D$.

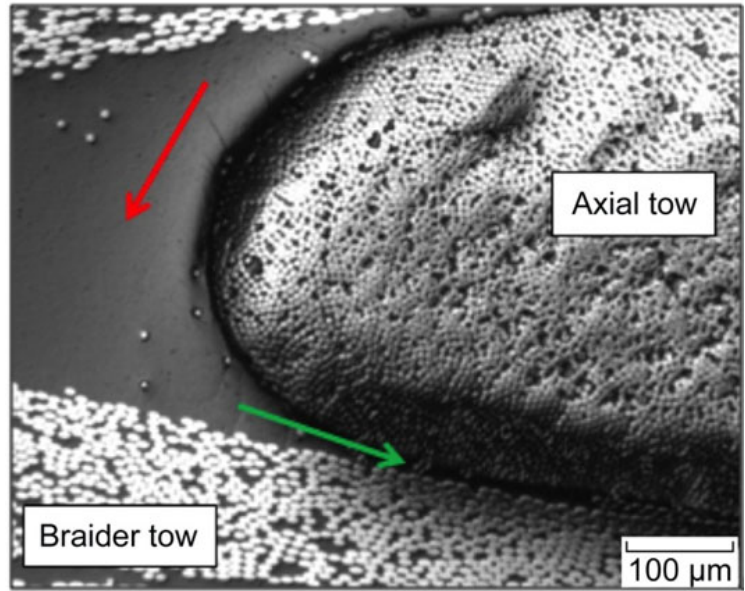

Figure 4.-Cross-section micrograph of the braided composite, at $100 \times$ magnification, displaying matrix pockets adjacent and parallel to the fiber tows.

discretization of the pure matrix model was that the $\mathrm{B}$ and $\mathrm{D}$ subcells containing only the braider tow plies were modeled as symmetric $\left[-60^{\circ} /+60^{\circ} /-60^{\circ}\right]$ and $\left[+60^{\circ} /-60^{\circ} /+60^{\circ}\right]$ laminates. Figure 3 shows a detailed schematic highlighting the overlapping of $+60^{\circ}$ and $-60^{\circ}$ tows in subcells $\mathrm{B}$ and $\mathrm{D}$. Although the orientation of the overlap differs between the subcells, they both contain equal amounts of $\pm 60^{\circ}$ and $-/+60^{\circ}$ tow regions within the entire subcell. Although the local green/yellow triangular regions on the braid are locally unsymmetric, one can approximate that these two subcells are symmetric with respect to the subcell discretization.

A limitation of the pure matrix model, however, is the fact that the pure matrix pockets contained between the UD plies do not accurately represent the true interaction of pure resin pockets with adjacent fiber tows. Figure 4 presents a cross-sectional micrograph of the braided composite with a red arrow indicating a pure matrix region adjacent to an axial fiber tow and a green arrow indicating matrix rich regions between axial and braider tows. From the micrograph images, more pure matrix regions are found lying in-plane to either the braider or axial tow rather than sandwiched between braider and axial tows as is modeled in the pure matrix model in Figure 2(b). Despite this deficiency, the pure matrix model is used as a comparative reference to a new absorbed matrix model.

\subsection{Absorbed Matrix Model}

In an attempt to combine aspects of both the previous semi-analytical models with that of the pure matrix model, it was decided that a suitable subcell discretization would contain the following elements:

1. Explicit modeling of UD layers

2. Accurate subcell fiber volume fractions

3. Symmetric B/D subcells

4. Better matrix representation

The absorbed matrix model utilizes the straight line model used by Xiao et al. for determining fiber volumes in each subcell for the axial and braider directions. Rather than modeling pure matrix pockets as unique layers which are in parallel (that is, with respect to in-plane loading) to the UD fiber tow plies, the volume of pure matrix is "absorbed" by the surrounding UD fiber tow plies to create a homogenized representation of the tow/matrix interaction. This representation of the tow/matrix interaction is notably similar to the original subcell model in Figure 2(a), however, the fiber volume fraction of the braider plies in this model are now thought to best capture the amount of fibers in the respective subcells. Figure 5 compares the fiber volume fractions between the previous semi-analytical subcell models and those of the 
pure matrix and absorbed matrix models. Both the pure and absorbed matrix models have similar volume fractions since they are derived based on the same straight line model approach. Figure 5 shows fiber volume fraction totals (blue) for subcells A and B and fiber volume fractions segregated by direction (red and green). It should be noted that the volume fractions shown for the axial and braider plies are given with respect to the volume of the subcell, thus are not ply-level fiber volume fractions discussed later.

The geometric parameters required to use the straight line model for this braided composite system are given in Table 1. Both the pure matrix model and the absorbed matrix model are applied in the sections to follow for testing both in-plane stiffness properties and single ply coupon tests. The resulting subcell discretizations are presented in Tables 2 and 3, respectively. The necessary equations and figures for the straight line model used for computing the thicknesses in Tables 2 and 3 are presented in the Appendix. The thicknesses in Tables 2 and 3 are with respect to a total shell thickness of unity. It should be noted that the absorbed matrix model assumes that pure matrix pockets in subcells $\mathrm{A}$ and $\mathrm{C}$ are assimilated only into the $\pm 60^{\circ}$ plies. Thus, the axial UD ply in subcells $A$ and $C$ has a fiber volume fraction of 80 percent for both the pure matrix and absorbed matrix models. The next section will cover the numerical implementation of both models within LS-DYNA.

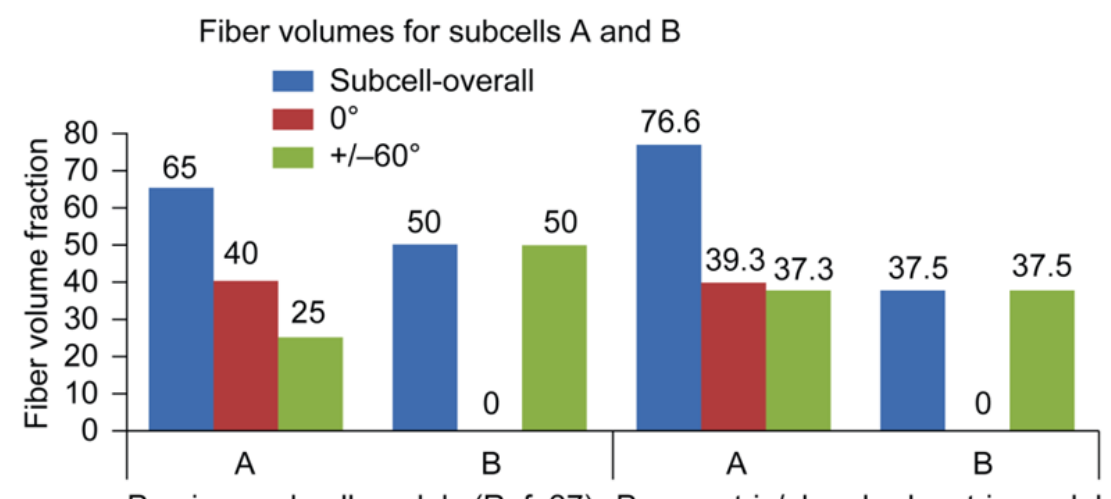

Previous subcell models (Ref. 27) Pure matrix/absorbed matrix model

Figure 5.-Comparison of fiber volume fractions at the subcell level between the previous subcell models and the pure matrix and absorbed matrix models.

TABLE 1.-GEOMETRICAL PARAMETERS USED FOR

CALCULATING THE LAMINA THICKNESSES

(T700/PR520 SYSTEM)

\begin{tabular}{|l|l|r|}
\hline Label & \multicolumn{1}{|c|}{ Description } & \multicolumn{1}{c|}{ Value } \\
\hline$W$ & Width of RUC (m) & 0.0089 \\
\hline$W_{A}$ & Width of cell A (m) & 0.004201 \\
\hline$W_{B}$ & Width of cell B (m) & 0.004765 \\
\hline$h$ & Ply thickness (m) & 0.00056 \\
\hline$V_{f, U D}$ & Fiber volume (tow) & 0.8 \\
\hline$n_{a}$ & Number of fibers in axial tow & 24000 \\
\hline$n_{b}$ & Number of fibers in braider tow & 12000 \\
\hline$d_{a}$ & Diameter of fiber filament in axial tow (m) & 0.000007 \\
\hline$d_{b}$ & Diameter of fiber filament in the braider tow (m) & 0.000007 \\
\hline$L$ & Height of unit cell (length) (m) & 0.0051 \\
\hline$\theta$ & Braid angle (degrees) & 60 \\
\hline
\end{tabular}


TABLE 2.-SUBCELL A \& B DISCRETIZATION FOR

THE PURE MATRIX MODEL

\begin{tabular}{|l|c|c|c|}
\hline Subcell A Lay-up & $\begin{array}{c}\text { Angle, } \\
\text { degree }\end{array}$ & $\begin{array}{c}V_{f}, \\
\text { percent }\end{array}$ & Thickness \\
\hline Braider tow & -60 & 80 & 0.2334 \\
\hline Matrix & --- & & 0.02123 \\
\hline Axial tow & 0 & 80 & 0.49074 \\
\hline Matrix & --- & --- & 0.02123 \\
\hline Braider tow & 60 & 80 & 0.2334 \\
\hline Subcell B Lay-up & --- & --- & ------- \\
\hline Braider tow & -60 & 80 & 0.1174 \\
\hline Matrix & --- & --- & 0.2652 \\
\hline Braider tow & 60 & 80 & 0.2348 \\
\hline Matrix & --- & --- & 0.2652 \\
\hline Braider tow & -60 & 80 & 0.1174 \\
\hline
\end{tabular}

TABLE 3.-SUBCELL A AND B DISCRETIZATION FOR THE ABSORBED MATRIX MODEL

\begin{tabular}{|l|c|c|c|}
\hline \multicolumn{1}{|c|}{ Subcell A Lay-up } & $\begin{array}{c}\text { Angle, } \\
\text { degrees }\end{array}$ & $\begin{array}{c}V f, \\
\text { percent }\end{array}$ & Thickness \\
\hline Braider tow & -60 & 73.0 & 0.255 \\
\hline Axial tow & 0 & 80.0 & 0.49 \\
\hline Braider tow & 60 & 73.0 & 0.255 \\
\hline Subcell B Lay-up & --- & ----- & ----- \\
\hline Braider tow & -60 & 37.5 & 0.25 \\
\hline Braider tow & 60 & 37.5 & 0.50 \\
\hline Braider tow & -60 & 37.5 & 0.25 \\
\hline
\end{tabular}

\subsection{Numerical Implementation}

\subsection{Material Models}

The work presented here focuses on single-ply coupon tests which remained within the elastic range of the composite, thus all plies in both subcell models required only elastic properties. However, in preparation for future work to identify a top-down approach for determining ply-level strength, viable candidates for material models were investigated and utilized in the work. The matrix material was assumed to be elastic, perfectly-plastic and was implemented within LS-DYNA using material type 24, *MAT_PIECEWISE_LINEAR_PLASTICITY. The matrix properties were taken from Table 4. The efficacy of the elastic, perfectly-plastic assumption was not validated here, and it should be noted that the explicit modeling of the matrix was not necessary for the absorbed matrix model. Two resident material models of LS-DYNA were identified as candidates for modeling the unidirectional composite material: Mat_54, a linear-elastic composite damage model, and Mat_58, a non-linear composite model utilizing a continuum damage mechanics (CDM) approach. The former utilizes the Chang-Chang failure criterion and models elastic/brittle failure in the fiber direction and an elastic, perfectly-plastic response in the transverse and shear matrix directions. The latter model uses a modified-Hashin failure criterion and a strain-driven CDM formulation developed by Matzenmiller (Ref. 31). A purely elastic composite response was simulated by setting arbitrarily high strength values in Mat_58 for all directions in the composite damage model, thereby requiring only updated elastic properties. For these stiffness values, a bottom-up micromechanics approach was employed to calculate the moduli and Poisson's ratio of the unidirectional layers in each of the subcells. In this way, the effective properties of the UD ply were determined based on the constituent properties of the fiber and matrix. The micromechanics software MAC/GMC developed at NASA GRC (Ref. 32) was used to compute the effective properties (elastic moduli, Poisson ratio) of the UD lamina based on the constituent properties provided in Table 4. It was hypothesized to be sufficient to use this bottom-up approach since the UD discretization of the sub-cell accurately captured the fiber contributions in all material axes present in the braided composite 
TABLE 4.-CONSTITUENT MATERIAL PROPERTIES

(REFS. 26 TO 28 AND 33)

\begin{tabular}{|c|c|c|c|c|c|}
\hline Material & $\begin{array}{c}\text { Density, } \\
\mathrm{g} / \mathrm{cm}^{3}\end{array}$ & $\begin{array}{c}\text { E11, } \\
\mathrm{GPa}\end{array}$ & $\begin{array}{c}\text { E22, } \\
\mathrm{GPa}\end{array}$ & $\begin{array}{c}\text { Poisson, } \\
\mathrm{v} 12\end{array}$ & $\begin{array}{c}\mathrm{G} 12, \\
\mathrm{GPa}\end{array}$ \\
\hline T700 & 1.8 & 230 & 15 & 0.2 & 27 \\
\hline PR520 & 1.256 & 4 & 4 & 0.4 & 1.47 \\
\hline 5208 & 1.263 & 3.8 & 3.8 & 0.4 & 1.36 \\
\hline 3502 & 1.266 & 3.6 & 3.6 & 0.4 & 1.29 \\
\hline E-862 & 1.2 & 2.7 & 2.7 & 0.4 & 1.0 \\
\hline
\end{tabular}

(a)

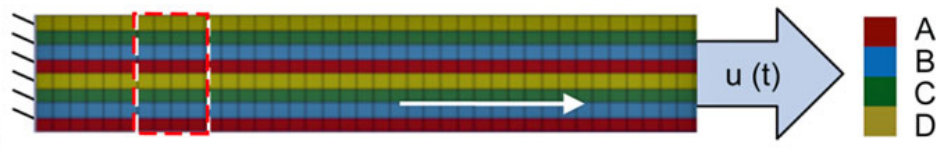

(b)

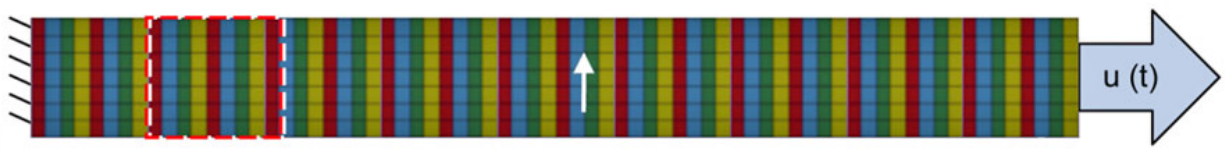

Figure 6.-FE mesh and boundary conditions for the (a) axial and (b) transverse coupons.

(particularly for in-plane loading). The process of determining the UD lamina properties was repeated depending on the number of UD fiber volume fractions present in the discretization. For example, the absorbed matrix model would involve computing effective properties using MAC/GMC for 37.5, 73, and 80 percent fiber volume fractions. The layered shell formulation within LS-DYNA would use laminate theory to determine the overall subcell response based upon the provided UD properties. This bottom-up process was used to compute the UD ply properties for four different material systems (T700 Toray fibers with different matrix systems: Cytec PR520, Cytec 5208, Hexcel 3502, Epon Epikote Resin 862, hereby referred to as E-862).

\subsection{Finite Element Model}

This section highlights the implementation of the layered subcell approach for modeling the braided composite within the FE code, LS-DYNA. Each of the individual subcells were modeled as unique parts composed of a layered, Belytschko-Tsay quadrilateral shell using the *INTEGRATION_SHELL keyword. Each layer was assigned a unique integration point and associated thickness according to the parameters provided in Table 2. Tensile coupon tests were simulated in both the axial direction (parallel to the axial tows) and the transverse direction (perpendicular to the axial tows). Axial coupon specimen geometries were 8 by 1.412 by 0.125 in. ( $\mathrm{H}$ by W by $\mathrm{D}, \mathrm{w} / 240$ elements) whereas the transverse coupon geometries were 12.002 by 1.4 by 0.125 in. (476 elements). These dimensions corresponded to a 6-ply specimen of the braided composite. Each shell element thus represented 6 plies of the braided composite and the total thickness of the shell was set to $0.125 \mathrm{in}$. It should be noted that in the real composite braid, nesting of axial fibers occurs and results in imperfect stacking. These effects are currently neglected and perfect layer stacking is assumed. The finite element models for the tensile tests are provided in Figure 6. The compression specimen geometries were 1 by 1.412 by 0.125 in. and 1.4 by 0.8714 by 0.125 in.

( $\mathrm{H}$ by $\mathrm{W}$ by $\mathrm{D}$ ) for the axial and transverse compression tests, respectively. The meshes for the axial and transverse compression tests used to compute the compressive moduli are shown by highlighted boxes in Figure 6. A white arrow in Figure 6, and in figures to follow, identifies the direction of the axial fiber tows. 


\subsection{Coupon Test Results}

The finite element results from the simulated coupon tests were used to compute effective properties of the braided composite for various matrix systems. Cross-sectional forces acting at the center gage of the specimen are used to compute the uniaxial stresses, whereas crosshead displacements are used for strain calculations. The stress-strain curves are then used to compute the moduli for the axial and transverse directions in both tension and compression. Table 5 displays the results for the E-862 and 3502 material systems. Shown are the predicted moduli for the pure matrix model, absorbed matrix model, previous subcell models (where available), and experimental test data. Table 6 presents similar data for the PR520 and 5208 material systems. General trends in the moduli predictions were that the axial tensile stiffnesses were slightly over-estimated ( $\sim 2.4$ percent $)$ and the transverse tensile stiffnesses were generally under-predicted ( $\sim 18$ percent). Despite little variation in the experimental transverse moduli across the material systems, the simulations were sensitive to the matrix modulus. The pure matrix model was slightly stiffer in all cases, due to the localization of the fibers in the 80 percent UD plies and its inherent effect on the subcell response. Both investigated subcell models adequately captured the stiffness properties even when compared against previous subcell works listed for the E-862 and PR520 systems in Tables 5 and 6 . The results for the compressive moduli varied across the material systems and between the transverse and axial directions. The transverse compression moduli were generally in better agreement ( $\sim 6$ percent), however, the axial compression moduli were only slightly over-predictive ( $\sim 13$ percent). For the case of compression, a similar trend in matrix moduli sensitivity was found for the transverse case, and an apparent softening in the absorbed matrix model in comparison to the pure matrix model was noticeable. Considering the purely predictive, bottom-up method of the proposed subcell models the moduli predictions were well within a reasonable range. Both the pure matrix and absorbed matrix models are investigated for their out-of-plane properties and verified against single ply coupon tests in the next section.

TABLE 5.-COMPARISONS OF COMPUTED MODULI WITH EXPERIMENTAL DATA FOR THE E-862 AND HEXCEL 3502 MATERIAL SYSTEMS

\begin{tabular}{|c|c|c|c|c|c|c|c|}
\hline & \multicolumn{4}{|c|}{ E-862 } & \multicolumn{3}{|c|}{3502} \\
\hline & $\begin{array}{l}\text { Pure } \\
\text { matrix }\end{array}$ & $\begin{array}{l}\text { Absorbed } \\
\text { matrix }\end{array}$ & $\begin{array}{l}\text { Previous works, } \\
\text { (Ref. 30) }\end{array}$ & $\begin{array}{c}\text { Test, } \\
\text { (Ref. 34) }\end{array}$ & $\begin{array}{l}\text { Pure } \\
\text { matrix }\end{array}$ & $\begin{array}{c}\text { Absorbed } \\
\text { matrix }\end{array}$ & $\begin{array}{c}\text { Test, } \\
\text { (Ref. 30) }\end{array}$ \\
\hline $\mathrm{E} 11 \mathrm{~T}(\mathrm{GPa})$ & 48.92 & 47.32 & 51.10 & 46.9 & 49.52 & 48.41 & 47.2 \\
\hline $\mathrm{E} 22 \mathrm{~T}(\mathrm{GPa})$ & 32.36 & 31.43 & 38.60 & 41.6 & 34.53 & 32.39 & 40.6 \\
\hline $\mathrm{E} 11 \mathrm{C}(\mathrm{GPa})$ & 50.31 & 48.64 & ------- & 41.4 & 51.45 & 49.26 & 41.8 \\
\hline $\mathrm{E} 22 \mathrm{C}(\mathrm{GPa})$ & 38.44 & 34.80 & ------- & 42.7 & 40.94 & 36.86 & 41.1 \\
\hline
\end{tabular}

TABLE 6.-COMPARISONS OF COMPUTED MODULI WITH EXPERIMENTAL DATA FOR THE CYTEC 5208 AND PR520 MATERIAL SYSTEMS

\begin{tabular}{|c|c|c|c|c|c|c|c|}
\hline & \multicolumn{3}{|c|}{5208} & \multicolumn{4}{|c|}{ PR520 } \\
\hline & Pure matrix & $\begin{array}{c}\text { Absorbed } \\
\text { matrix }\end{array}$ & $\begin{array}{c}\text { Test } \\
\text { (Ref. 34) }\end{array}$ & $\begin{array}{l}\text { Pure } \\
\text { matrix }\end{array}$ & $\begin{array}{c}\text { Absorbed } \\
\text { matrix }\end{array}$ & $\begin{array}{l}\text { Previous works } \\
\text { (Refs. } 30 \text { and 27) }\end{array}$ & $\begin{array}{c}\text { Test } \\
\text { (Ref. 34) } \\
\end{array}$ \\
\hline E11T(GPa) & 49.858 & 48.905 & 47.5 & 51.496 & 49.22 & $51.1 / 44.9$ & 47.7 \\
\hline E22T (GPa) & 35.351 & 35.377 & 41.3 & 36.667 & 36.81 & $38.7 / 51.2$ & 42.7 \\
\hline $\mathrm{E} 11 \mathrm{C}(\mathrm{GPa})$ & 51.744 & 50.037 & 44.6 & 52.154 & 51.20 & ------------- & 47.6 \\
\hline $\mathrm{E} 22 \mathrm{C}(\mathrm{GPa})$ & 41.42 & 39.790 & 38.6 & 42.434 & 41.76 & ------------ & 42.0 \\
\hline
\end{tabular}




\subsection{Single Ply Coupon Tests and Simulations}

Previous works have investigated the out-of-plane displacements in single-ply coupon tests of the braided composite under axial and transverse tension (Ref. 2) using Digital Image Correlation (DIC) on the T700/E862 braided composite. The displacements were a result of the locally unsymmetric nature of the braided composite. The DIC images of the out-of-plane displacements are reproduced in Figures 7(a) and (b). In light of these results, it was conjectured that a modeling approach best capturing this phenomenon would be advantageous for two reasons. One, it would provide a means of quantifying the flexural property predictions of the subcell model. Second, it would suggest that the subcell model may be sufficient in capturing the effects of inter-ply delamination hypothesized to be caused by these out-ofplane deformations. These edge-related delaminations drastically affect the stress/strain distribution in the gage section of standard test coupons (Ref. 2) and accurate simulations of these phenomena may provide insight into obtaining valuable strength data from material characterization tests.

\subsection{Subcell Flexural Properties}

CLPT was used initially to determine the anticipated response of the two subcell discretizations (pure matrix and absorbed matrix models). This analysis would provide insight into the out-of-plane properties of the subcells and would allow for meaningful interpretation of the single ply coupon simulations. Two subcell characteristics were identified as potential contributors to the out-of-plane deformations and studied using CLPT: the tension/twist coupling of subcells A and C and the flexural modulus of subcell B and $\mathrm{D}$. To quantify the tension twist coupling under uniaxial loading, relations (1) and (2) below were used- whereby assumptions of uniaxial stress and zero membrane moments provided a relation between membrane strain, $\varepsilon_{x}$ or $\varepsilon_{y}$, and the twist curvature, $k_{x y}$. The x-direction corresponds to that of the axial tows $\left(0^{\circ}\right)$, and the y-direction corresponds to the transverse direction perpendicular to the axial tows.

Equation (1) represents the tension-twist coupling for uniaxial tension in the x-direction. Conversely, Equation (2) is used for the case of uniaxial tension in the y-direction. The quantities $T_{x}^{*}$ and $T_{y}^{*}$ represent the linear relation between membrane strain and curvature for the cases of uniaxial loading in the axial and transverse directions, respectively. The quantities $B_{16}$ and $B_{26}$ are the only non-zero components of the extensional-bending coupling matrix of the subcell laminate; it is for this reason the curvatures are reduced to only $k_{x y}$ for the case of uniaxial tension. The computed results for the two discretization

$$
\begin{aligned}
& k_{x y}^{0}=\left(\frac{\frac{A_{12}}{A_{11}} B_{26}-B_{16}}{D_{66}}\right) \in_{x}^{0}=T_{x}^{*} \in_{x} \\
& k_{x y}^{0}=\left(\frac{\frac{A_{12}}{A_{22}} B_{16}-B_{26}}{D_{66}}\right) \in_{y}^{0}=T_{y}^{*} \in_{y} \\
& E_{i j}^{f}=\frac{1}{d_{i j}^{*}}=\frac{12}{h^{3}[D]_{i j}^{-1}}, \text { for } i, j \in 1,2
\end{aligned}
$$




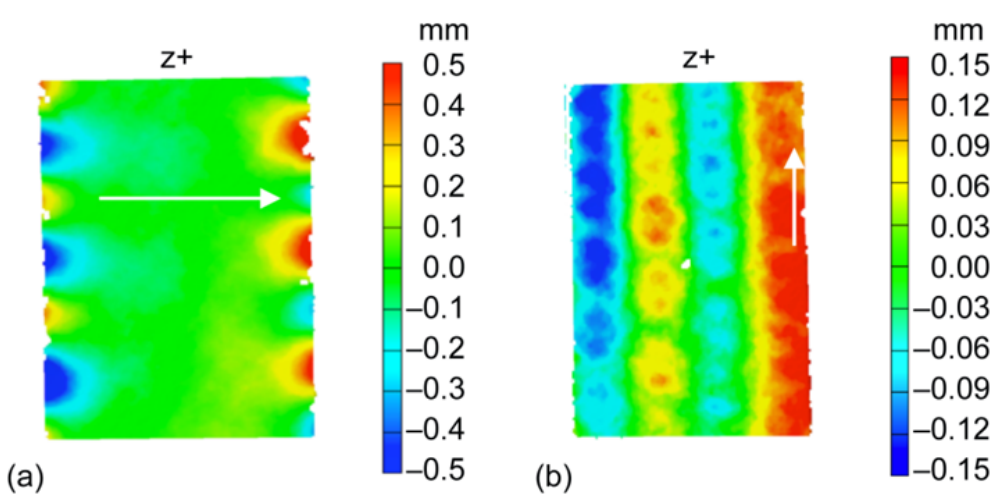

Figure 7.-z+ displacement contours obtained using DIC for (a) single ply transverse tensile tests and (b) single ply axial tensile tests.

TABLE 7.-TENSION TWIST COUPLING

IN SUBCELL A

\begin{tabular}{|l|c|c|}
\hline \multicolumn{1}{|c|}{ Model } & $T_{x}{ }^{*}$ & $T_{y}^{*}$ \\
& $(1 / \mathrm{m})$ & $(1 / \mathrm{m})$ \\
\hline Pure matrix & -5800.64 & -1216.6 \\
\hline Absorbed matrix & -5983.83 & -1208.43 \\
\hline
\end{tabular}

TABLE 8.-PREDICTED FLEXURAL MODULI

OF SUBCELL B

\begin{tabular}{|l|c|c|c|}
\hline \multicolumn{1}{|c|}{ Model } & $\begin{array}{c}E_{x}^{f} \\
(\mathrm{GPa})\end{array}$ & $\begin{array}{c}E_{y}^{f} \\
(\mathrm{GPa})\end{array}$ & $\begin{array}{c}E_{x y}^{f} \\
(\mathrm{GPa})\end{array}$ \\
\hline Pure matrix & 9.48 & 21.37 & 7.91 \\
\hline Absorbed matrix & 6.53 & 21.01 & 10.4 \\
\hline
\end{tabular}

TABLE 9.-COMPARISON OF BENDING

STIFFNESS MATRICES FOR SUBCELL B

\begin{tabular}{|r|r|r|r|r|r|}
\hline \multicolumn{3}{|c|}{ Pure matrix model } & \multicolumn{3}{c|}{ Absorbed matrix model } \\
\hline 0.2324 & 0.2921 & -0.1558 & 0.2966 & 0.1403 & 0.5667 \\
\hline 0.2921 & 0.9500 & -0.4372 & 0.1403 & 0.2112 & 0.4890 \\
\hline-0.1558 & -0.4372 & 0.3201 & 0.5667 & 0.4890 & 0.2203 \\
\hline
\end{tabular}

models, shown in Table 7, highlight the minute differences between the pure and absorbed matrix models in terms of the quantities $T_{x}{ }_{x}$ and $T^{*}$. The flexural moduli of subcell B for the two discretizations were computed using Equation (3) and the results are presented in Table 8. The flexural moduli in the $x$ and $x y$ directions varied considerably between the subcell discretizations, however the flexural moduli for the transverse, $y$, direction were nearly identical for both models. This similarity in transverse flexural moduli was contrary to the unambiguously different $D$ matrices (bending-stiffness matrices) computed for the two methodologies, shown in Table 9.

\subsection{Numerical Verification of Single Subcell Responses}

The curvatures seen in Figure 7(a) and (b) were hypothesized to be a direct consequence of the tension-twist coupling present in the unsymmetric subcells A and C. Thus, it was necessary to ensure the LS-DYNA implementation of the subcell models captured this phenomenon and to determine any mesh and/or element-type dependencies. Due to little expected differences between the two subcell discretizations in the tension/twist responses of subcells $\mathrm{A}$ and $\mathrm{C}$, only the pure matrix model was used in the simulations to follow and shown in Figures 8 and 9. Figure 8(a) and (b) present the contour plots of out-of-plane displacement for subcell A under uniaxial tension. As can be seen from the contours, the displacements in the $y$ and $z$ directions were unrestrained. There was noticeable smoothing in the contours 


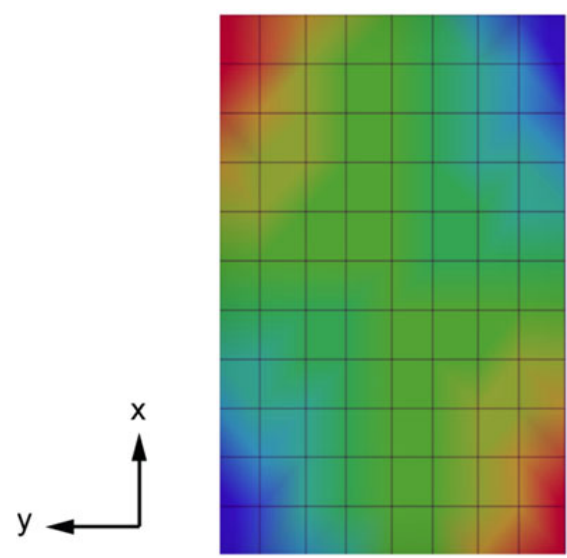

(a)

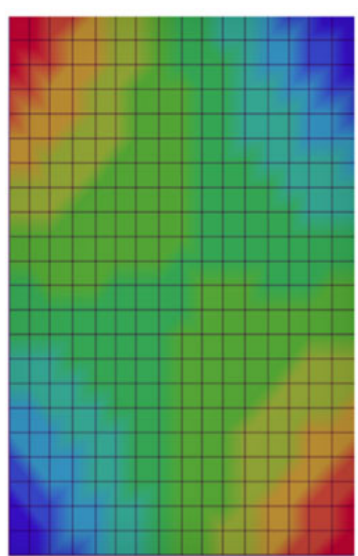

(b)

Figure 8.-Contour plots of subcell A's out-of-plane z-displacement due to uniaxial tension in the axial (x) direction for (a) a coarse mesh and (b) a more refined mesh. Displacements in the $y$ and $z$ directions are unrestrained on all boundaries. The red and blue spectrums on the contour plots represent positive and negative z-displacements, respectively. Results are qualitative, thus no fringe scales are displayed. Shell elements are Belytschko-Tsay.

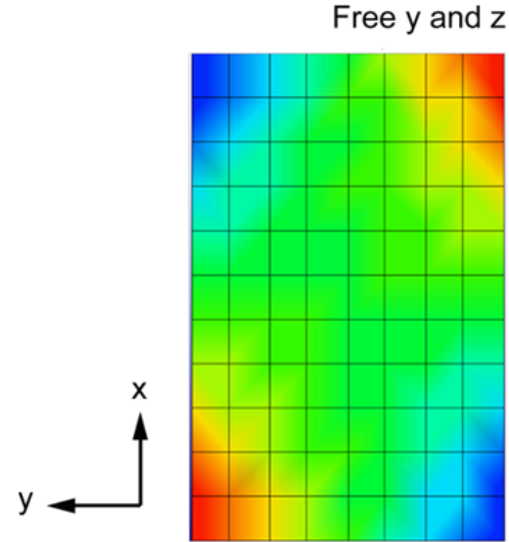

(a)

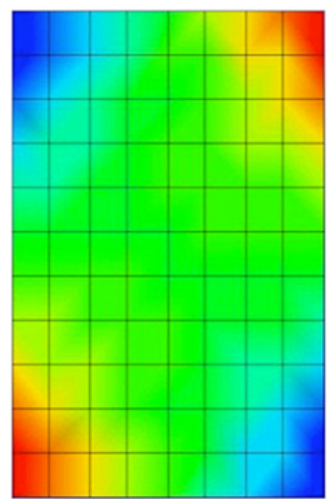

(b)
Fixed y and $z$ displacements

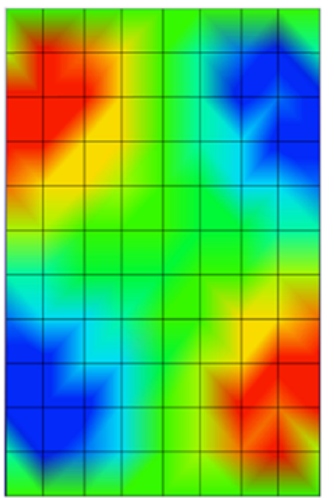

(c)

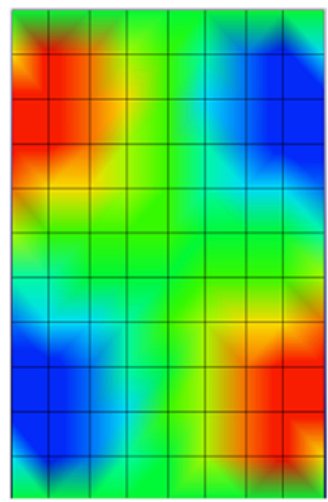

(d)

Figure 9.-Contour plots of subcell C's out-of-plane z-displacement due to uniaxial tension in the axial (x) direction. The four contour plots show comparisons for unrestrained y and $z$ displacements with (a) Belytschko-Tsay and (b) Belytschko-Leviathan shell elements, and fixed y and $z$ displacements at the top and bottom boundaries for

(c) Belytschko-Tsay and (d) Belytschko-Leviathan shell elements.

as a function of increased mesh dependency; however, the size and magnitude of the deformation were unchanged. The out-of-plane deformations were as expected from the laminate analysis reported previously with only twist curvature, $k_{x y}$, present in the case of uniaxial tension. The various contour plots in Figure 9 for subcell $\mathrm{C}$ highlight the effects of edge boundary conditions on the displacements as well as the influence of shell element formulation. Two shell formulations were investigated, Belytschko-Tsay and Belytschko-Leviathan, based on recommendations in literature for modeling unbalanced and unsymmetric lamina in LS-DYNA (Ref. 35). In the case of free $y$ and $z$ displacements on the top and bottom surfaces of the subcell, the two element formulations produced nearly identical results. When the $y$ and $z$ displacements were fixed on the top and bottom boundaries, a reversal in twist was observed. Due to the complex nature of the induced curvatures, only Belytschko-Leviathan shells obtained smooth contour plots seen in Figure 9(d). In contrast, the Belytschko-Tsay elements had noticeable sharp, lined features which appear to be a function of the element size, highlighted in Figure 9(c). It should also be 
mentioned that comparing Figure 9(a) with Figure 8(a) indicates that the out-of-plane deformation of subcells $\mathrm{A}$ and $\mathrm{C}$ have reflective symmetry with respect to each other. Based on the performance of the Belytschko-Leviathan shells, it was deemed that the LS-DYNA layered shell implementation of the subcell discretizations were sufficient to capture the necessary tension-twist mechanisms. BelytschkoLeviathan shell elements are utilized in the single ply coupon simulations to follow.

\subsection{Single Ply Coupon Simulations}

Full coupon simulations were performed for both axial and transverse tension using similar coupon dimensions from the earlier tensile specimens. In this study, the thicknesses of the shells were reduced to that of a single ply ( $\sim 0.022$ in.). The coupon mesh was refined to include 4 elements per subcell, shown in Figure 10(b), in comparison to that of the standard coupon tests in Figure 6(a) and (b). Belytschko Leviathan shell elements are used to better account for the tension-twist coupling of the unsymmetric subcells as discussed in the previous section. Both coupon specimens are loaded to 1 percent strain for which the composite response in the experiments was purely elastic. Thus, the currently elastic material models for the UD plies in each subcell are again deemed appropriate for capturing the out-of-plane effects.

Transverse coupon results are displayed in Figure 10(a) and (c) for the pure matrix model and can be compared to mesh/subcell location using Figure 10(b). The two contour plots in Figure 10(a) and (c) represent two alternating stable positions in the predicted solution, which tend to alternate through loading. Figure 10(a) contained the major curvatures and displayed similarities to the DIC results in Figure 7(a). Minor curvatures of opposite sign seen in Figure 10(c) also existed between the major curvatures that could be observed in the DIC data. Two distinct remarks could be made, qualitatively,
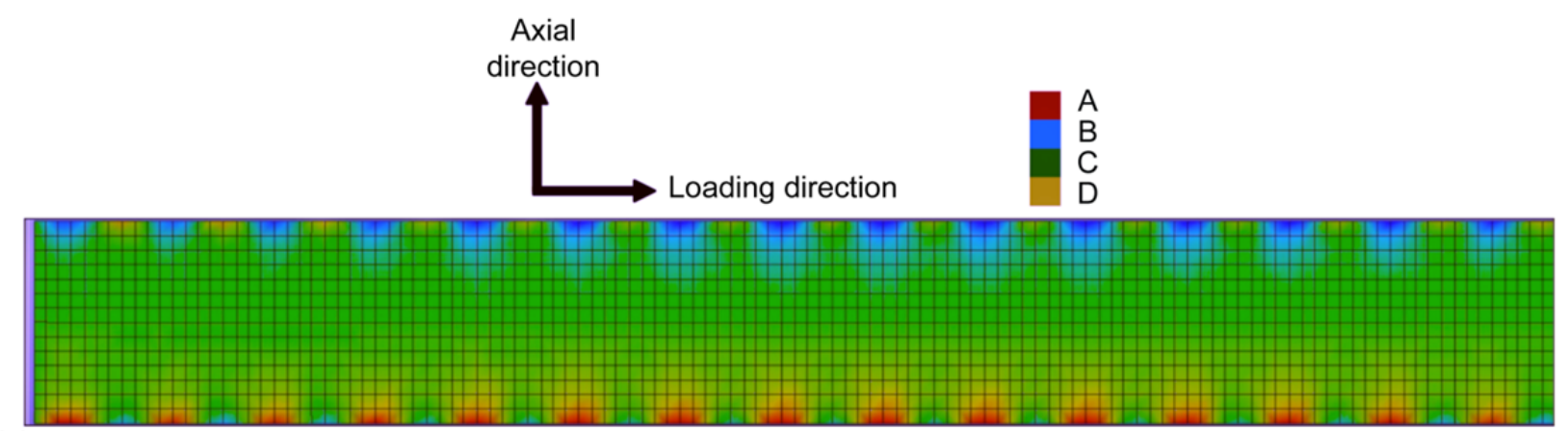

(a)

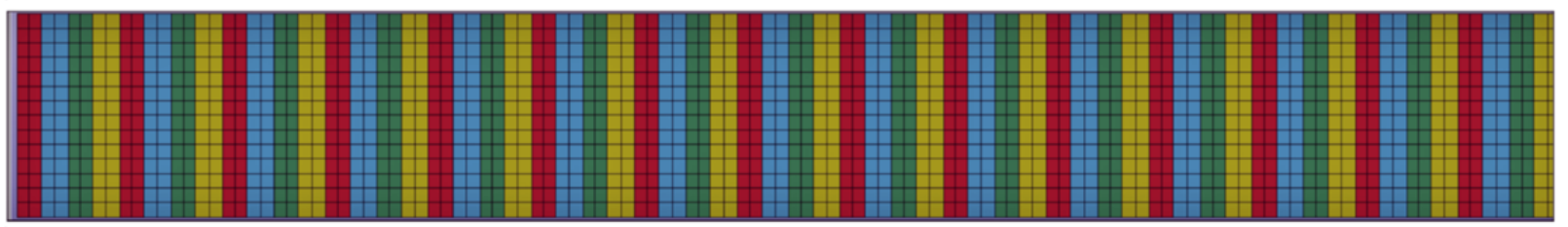

(b)

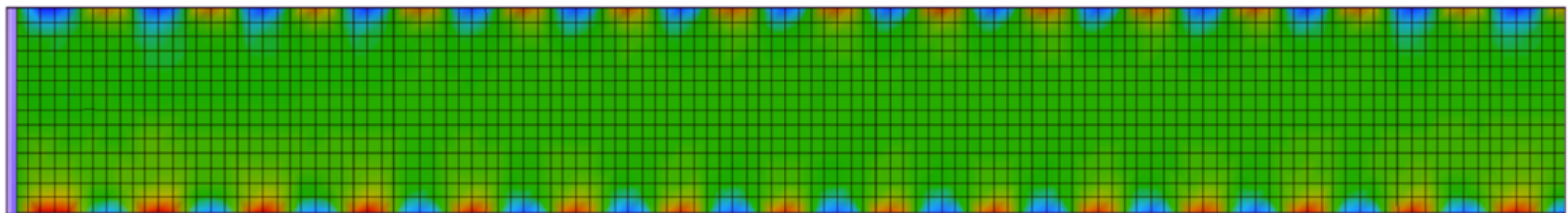

(c)

Figure 10.-Contour plots of z-displacement for a transverse coupon specimen loaded in the y-direction. Axial fiber tows are oriented in the x-direction. (a) Stable position with only major curvatures displayed, (b) coupon mesh for comparing location of displacements with respect to the subcells, and (c) a stable position with both minor and major curvatures. The meshes in (a) through (c) are aligned for comparisons. Results are qualitative, thus no fringe scales are displayed. 


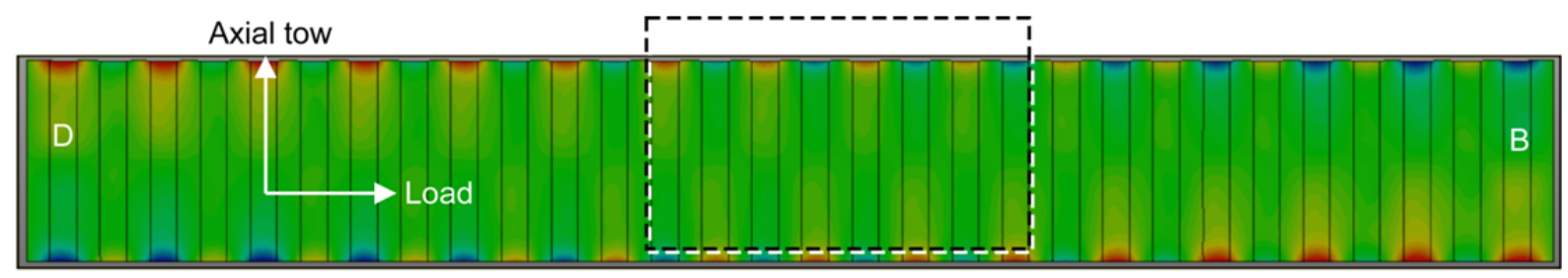

Figure 11.-Contour plots of z-displacement for a transverse coupon specimen loaded in the y-direction and axial fiber tows oriented in the x-direction. The B/D subcells closest to left and right boundaries are labeled accordingly. The dashed box highlights a transitional region where the location of major curvatures is switching.

from the contour results. First, edge twisting resulted from a collective effect of subcells $\mathrm{A}$ and $\mathrm{C}$ and the reflective symmetry of their tension-twist coupling. Consequently, significant edge displacements, although rooting from the twisting of subcells $\mathrm{A}$ and $\mathrm{C}$, were manifested in subcells $\mathrm{B}$ and $\mathrm{D}$. In Figure 10(c), the major curvatures occurred in the regions of subcell B, whereas the minor curvatures occurred within subcells D. This feature was determined to be a consequence of boundary conditions and the relative adjacency of either of these subcells with the restrained edge. For example, modifying the order of subcells so that subcell $\mathrm{C}$ would be the first from the constrained edge - that is, if looking left to right in Figure 10(b) - would move the location of the major curvatures to subcells D. This shifting of subcells was performed and the single ply transverse tension simulation is given in Figure 11. The z-displacement contours shown in Figure 11 provide an example of competing major/minor curvatures between subcell B and D by varying the subcell closest to the restrained edge (labeled on the figure). The left hand side of Figure 11 features dominant positive (red) displacement curvatures at the top of the model, whereas beyond the dashed transitional region marked on the figure the dominant displacement curvatures at the top of the model are negative (blue). Though the source of major/minor curvatures was found to be a function of boundary condition, the alternating stable contours between those in Figure 10(a) and (c) were thought to be a construct of the numerical implementation. The contours seen experimentally were entirely stable and matched closely to that of Figure 10(c), and thus supported this deduction. These results highlight the importance of the finite element model's constraints on the out-ofplane displacement contours in the modeling approach, a phenomenon which must be acknowledged when comparing experimental and numerical results.

A quantitative comparison of the z-displacements for the two subcell models is displayed in Figures 12(a) to (c) with the full field DIC data presented again in Figure 12(d). The results are presented using the stable contour shape from Figure 10(c), which are found to match closely to those seen experimentally. Two different element sizes are provided for the absorbed matrix model, Figure 12(a) and (b), to show the effect of a mesh refinement on smoothing the displacement contours. Note that all four contour plots match to the fringe levels shown at the right of Figure 12. As expected from the single subcell tests, the finer discretization, although smoothing the contours, did not alter the magnitude of the z-displacements. Comparing the two subcell models, the pure matrix model showed a significant reduction in out-of-plane deformation. Despite the pure matrix model showing qualitatively accurate curvatures in Figures 10 and 11, the contours were underpredicted in comparison to the experimental results. Based on the earlier investigations using CLT, the probable cause of the suppression of the out-ofplane displacements in the pure matrix model was the divergent properties of the bending stiffness matrix components between the two discretizations. The pure matrix model had a 145 percent higher flexural modulus in the axial fiber direction than the absorbed matrix counterpart, despite there being almost no differences in the tension-twist coupling of subcell A between the two models. Thus, the stiff outer UD plies in subcell B of the pure matrix model are acting like composite sandwich skin layers, suppressing the outof-plane deformation. The z-displacements predicted by the absorbed matrix model for both element discretizations in Figure 12(a) and (b) were in good agreement with the experimental results in Figure 12(d). 


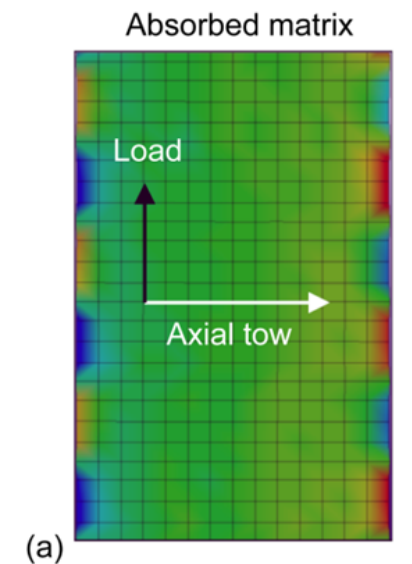

(a)

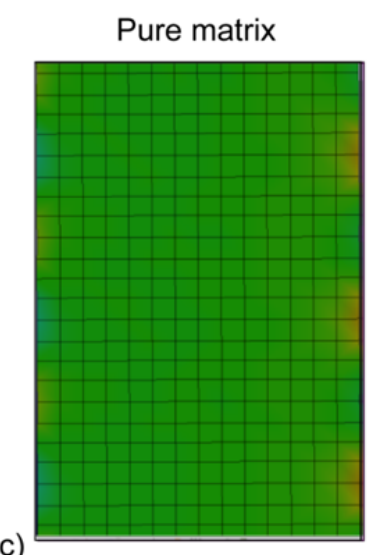

(b)

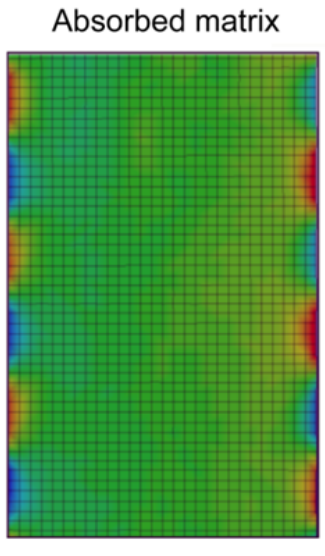

\section{Experiment}

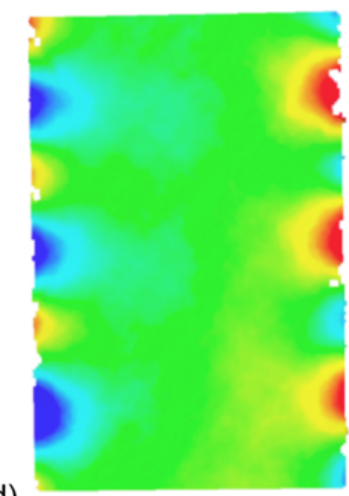

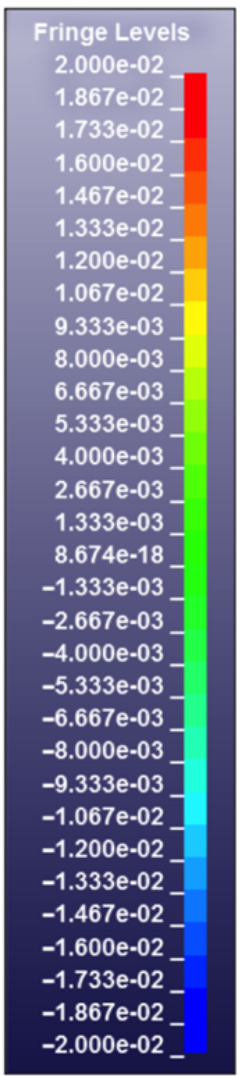

(d)

Figure 12.-Comparisons of z-displacement for absorbed matrix model with both (a) a coarse mesh and (b) a fine mesh; (c) pure matrix model with a coarse mesh; and (d) experimental DIC data (Ref. 2). The units of the LS-DYNA contour legend are in inches and are equivalent to that of the DIC results (originally presented in Figure $7(\mathrm{a})$ in $\mathrm{mm}$ ).

The z-displacement contour plots for axial coupon simulations are shown in Figure 13. The axial coupon was meshed coarsely with two elements per subcell width, similar to that of the transverse case shown in Figure 12(a). Although there were out-of-plane displacements occurring near the gripped ends of the coupon, readily apparent in the absorbed matrix model — the results did not mimic the convex/ concave undulations throughout the body of the coupon as seen experimentally in Figure 7(b). The nature of the tension-twist coupling of subcells A and C permitted twist deformations only at the corners of the subcells due to anti-symmetry, thus almost no out-of-plane deformations were observed in the interior of the model. It must be mentioned that the contour plots from the LS-DYNA simulations in Figure 13(a) and (b) are on a scale 1/6th that of the contour plots in the experimental data in Figure 7(b). Thus, although these deformations are present within the single ply and may contribute to internal stresses within the 6-layer braid, the effects of the axial undulations are not as significant to coupon damage, unlike the edge twist in the transverse single ply coupons. Consequently, it was concluded that the mechanisms driving the concave/convex curvatures seen experimentally in the axial coupon tests arose from physical mechanisms other than the locally unsymmetric nature of the single-ply braided composite. It is thought that capturing concave/convex curvatures in the axial coupon simulations requires a methodology preserving fiber continuity. Due to the nature of the discretization and the resulting discontinuity of fiber tows, capturing curvature phenomena like those seen in Figure 7(b) is a limitation to the current subcell approach. 


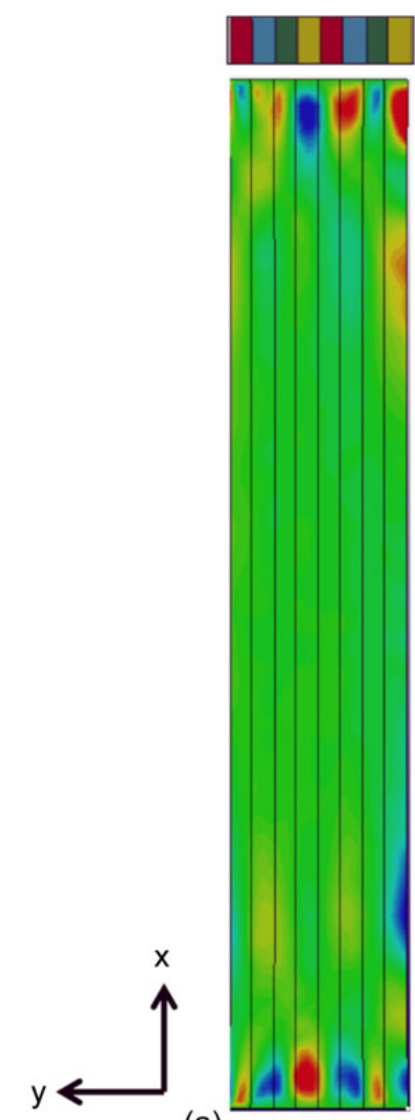

(a)

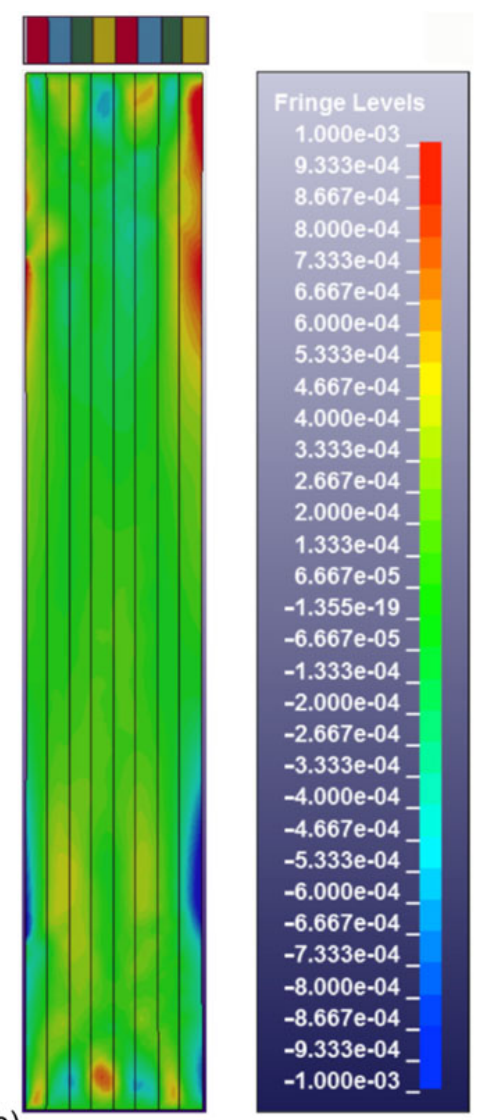

(b)

Figure 13.-Contour plots of z-displacement for axial coupon tests (load applied in fiber, or x-direction) for (a) the absorbed matrix model and (b) the pure matrix model. Units of the contour legend are in inches.

\subsection{Conclusion}

Based on the results from the single ply coupon tests, the absorbed matrix model was found to be an excellent candidate for future advancements in the semi-analytical approach. The adequate moduli prediction in both tension and compression, as well excellent agreement in out-of-plane tension-twist displacements, under global transverse loading, were based purely on constituent properties, thus highlighting the efficacy of the model to be extended to other material systems. The analysis of the flexural properties of the subcell discretizations was a novel contribution and provided insight into the mechanisms driving the out-of-plane deformations seen in the transverse coupon tests. It was found that the unsymmetric $\mathrm{A}$ and $\mathrm{C}$ subcell laminates were the direct cause of the unique material response. The excellent correlation with the experimental DIC data for the transverse coupon case supported the subcell discretization utilized in the absorbed matrix model, which left subcells B and D as symmetric laminates. The single ply coupon results also verified the assumption that the matrix was best modeled in series with surrounding braider tows, rather than in parallel as in the pure matrix model. The subcell model, however, was not able to capture the axial out-of-plane responses in the single ply simulations and was attributed to a limitation of the overall discretization scheme. Although very slight differences were found between the two subcell models for in-plane properties, significant differences in the axial flexural modulus contributed to varying tension-twist responses in the single ply. Lastly, the current method which preserves the through-thickness subcell properties should be beneficial when performing impact simulations. 
The current semi-analytical subcell approach has several advantages over that of the previous iterations, summarized in Section 2.0. Most important, however, is the possibility of using the current subcell implementation to better understand the braided coupon's edge related damage, currently a limiting constraint in determining material strength parameters. In conjunction with understanding coupon damage mechanisms, future work will look to develop a top-down methodology in order to determine the necessary UD ply strengths for the absorbed matrix subcell discretization. 


\section{Appendix-Straight Line Braided Composite Model}

The straight line model (Ref. 29) for determining the necessary UD ply thicknesses and computing the volume of fibers in the axial and braider directions contained in the subcells is presented here. The subcell widths $W_{A}$ and $W_{B}$ are measured as shown in Figure A1. Figure A1 also shows the amounts of $+60^{\circ}$ braider tow (dashed yellow box) approximated to exist inside of the subcell dimensions highlighted by the green box.

Equations (4) to (6) are used to compute the volume of fiber contained in subcells A or B (the quantity of fibers in $\mathrm{C}$ and $\mathrm{D}$ will be identically equivalent). The subscripts $a$ and $b$ designate axial or braider tow and A and B subscripts designate the corresponding subcell. Superscript $f$ represents volume of fibers whereas the subscript $f$ represents volume fraction. The tow subscript represents the fiber tow, $m$ the matrix layer, $L$ the length of the subcell shown in Figure A1, and $h$ the height of the subcell through the thickness as shown in Figure A2.

$$
\begin{gathered}
V_{a A}^{f}=\frac{\pi d_{a}^{2}}{4} n_{a} L \\
V_{b A}^{f}=\frac{\pi d_{b}^{2}}{2} n_{b}\left(l_{b A}\right)=\frac{\pi d_{b}^{2}}{2} n_{b}\left(\frac{W_{A}}{\sin \theta}\right) \\
V_{b B}^{f}=\frac{\pi d_{b}^{2}}{4} n_{b}\left[\left(l_{b B}\right)^{2}+h^{2}\right] 0.5=\frac{\pi d_{b}^{2}}{4} n_{b}\left[\left(\frac{W_{B}}{\sin \theta}\right)^{2}+h^{2}\right]^{0.5} \\
V_{k l}=\frac{V_{k l}^{f}}{V_{f, \text { tow }} W h L^{\prime}} \text { for } k=a, b ; l=A, B \\
V_{m, l}=1-\sum_{k} V_{k l}
\end{gathered}
$$

Equations (7) and (8) compute the UD ply thicknesses for the pure matrix model. In both subcell models, the volume fractions of the three different UD plies (axial tow in A, braider tows in A, and braider tows in B) are computed according to Equations (9) to (11). The thickness of the axial UD in subcell $\mathrm{A}$ is assumed to be equivalent to the original pure matrix model; however, the braider UD plies in both $\mathrm{A}$ and $\mathrm{B}$ are modified according to Equations (12) and (13).

$$
\begin{gathered}
V_{f, a A}=V_{f, \text { tow }} \\
V_{f, b A}=\frac{V_{b A}^{f}}{\left(1-V_{a A}\right)} \\
V_{f, b B}=\frac{V_{b B}^{f}}{W_{B} h L} \\
V_{b A}^{*}=V_{b A}+V_{m A} \\
V_{b B}^{*}=V_{b B}+V_{m B}
\end{gathered}
$$




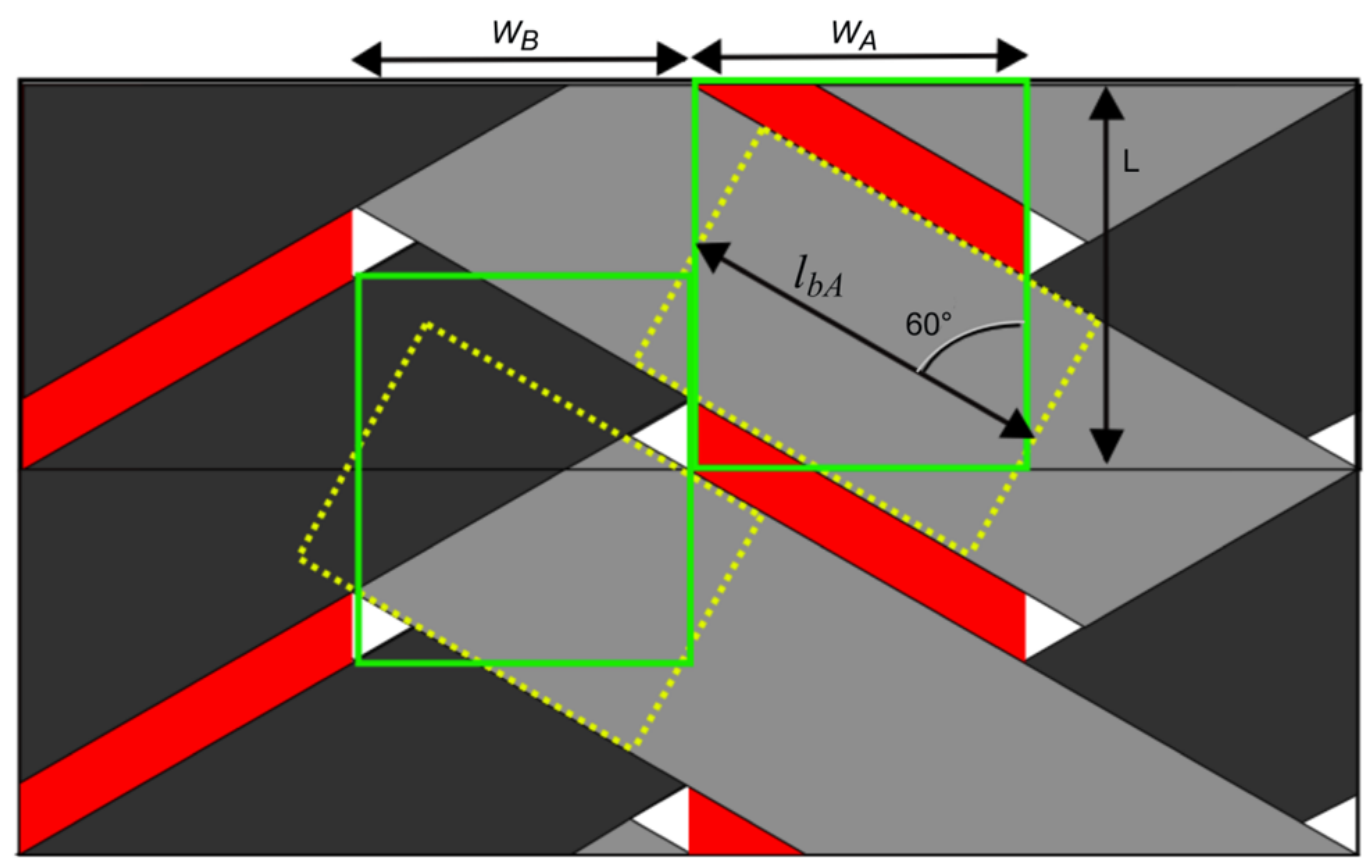

Figure A1.-Two unit cells of the braided composite are shown with the widths of subcells $A$ and $B$ labeled. The green boxes represent the size of a subcell, whilst the dotted yellow boxes represent the amount of braider tow contained within the subcell volume as a straight section of fiber tow.

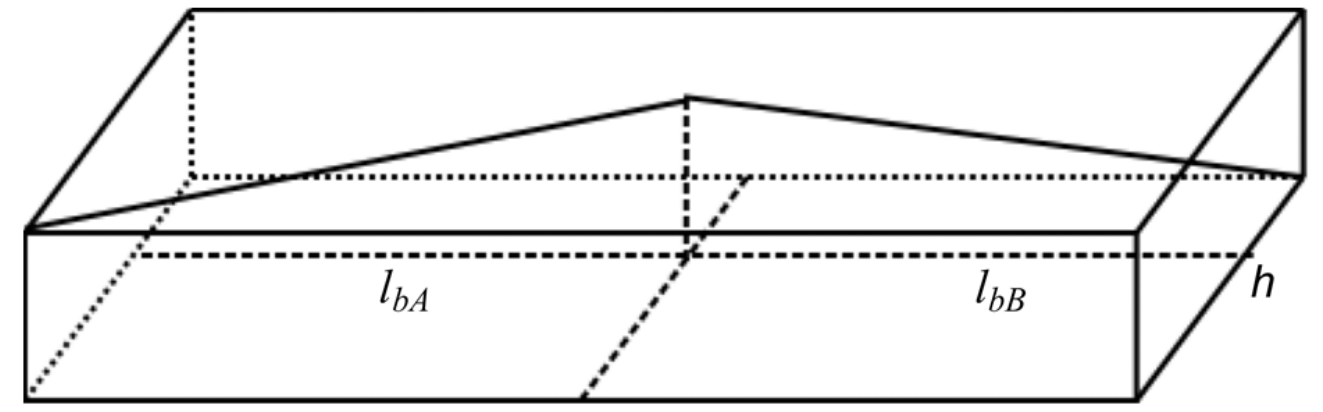

Figure A2.-Schematic of the braider fiber tow lengths approximated by the straight line mode for subcells $A$ and $B$. 


\section{References}

1. Roberts, G.D., Goldberg, R.K., Binienda, W.K., Arnold, W.A., Littell, J.D., and Kohlman, L.W., "Characterization of triaxial braided composite material properties for impact simulation," American Helicopter Society (NASA/TM-2009-215660), Grapevine, TX, 2009, pp. 2507-2528.

2. Kohlman, L.W., "Evaluation of Test Methods for Triaxial Braid Composites and the Development of a Large Multiaxial Test Frame for Validation Using Braided Tube Specimens," Dissertation, University of Akron, 2012.

3. Hallquist, J.O., "LS-DYNA Theory Manual," 2006.

4. Ishikawa, T., and Chou, T.-W., "Stiffness and strength behaviour of woven fabric composites," Journal of Materials Science, vol. 17, 1982, pp. 3211-3220.

5. Ishikawa, T., and Chou, T.-W., "One-Dimensional Micromechanical Analysis of Woven Fabric Composites," AIAA Journal, vol. 21, 1983, pp. 1714-1721.

6. Naik, R.A., "Failure analysis of woven and braided fabric reinforced composites," Journal of Composite Materials, vol. 29, 1995, pp. 2334-2363.

7. Naik, N.K., and Shembekar, P.S., "Elastic Behavior of woven fabric composites," Journal of Composite Materials, vol. 26, 1992, pp. 2196-225.

8. Yang, J.M., Ma, C.L., and Chou, T.W., "Fiber inclination model of three-dimensional textile structural composites," Journal of Composite Materials, vol. 20, 1986, pp. 472-84.

9. Branch, K., Shivakumar, K., and Awa, V.S., "Three-dimensional tow inclination model for calculating elastic constants of three-dimensional triaxial braided composites," AIAA/ASME/ ASCE/AHS/ASC Structures, Structural Dynamics and Materials Conference, Salt Lake City, UT; United States: 1996, pp. 1788-1803.

10. Redman, C.J., and Douglas, C.D., "Theoretical prediction of the tensile elastic properties of braided composites," 38th International SAMPE Symposium, 1993, pp. 719-27.

11. Ivanov, I., and Tabiei, A., "Three-dimensional computational micro-mechanical model for woven fabric composites," Composite Structures, vol. 54, 2001, pp. 489-496.

12. Ivanov, I., and Tabiei, A., "Three-dimensional computational micro-mechanical model for woven fabric composites," Composite Structures, vol. 54, 2001, pp. 489-496.

13. Ivanov, D.S., Baudry, F., Van Den Broucke, B., Lomov, S.V., Xie, H., and Verpoest, I., "Failure analysis of triaxial braided composite," Composites Science and Technology, vol. 69, Jul. 2009, pp. 1372-1380.

14. Huang, Z., "The mechanical properties of composites reinforced with woven and braided fabrics," Composites Science and Technology, vol. 60, 2000, pp. 479-498.

15. Huang, Z.-M., "Efficient Approach to the Structure-Property Relationship of Woven and Braided Fabric-reinforced Composites up to Failure," Journal of Reinforced Plastics and Composites, vol. 24, Aug. 2005, pp. 1289-1309.

16. Huang, Z.-M., Fujihara, K., and Ramakrishna, S., "Tensile stiffness and strength of regular braid composites: Correlation of theory with experiments," Journal of Composites Technology and Research, vol. 25, 2003, pp. 35-49.

17. Quek, S.C., Waas, A.M., Shahwan, K.W., and Agaram, V., "Analysis of 2D triaxial flat braided textile composites," International Journal of Mechanical Sciences, vol. 45, 2003, pp. 1077-1096.

18. Carey, J., Munro, M., and Fahim, A., "Longitudinal elastic modulus prediction of a 2-D braided fiber composite," Journal of Reinforced Plastics and Composites, vol. 22, 2003, pp. 813-831.

19. Masters, J.E., Foye, R.L., Pastore, C.M., and Gowayed, Y.A., "Mechanical properties of triaxially braided composites: Experimental and analytical results," Journal of Composites Technology and Research, vol. 15, 1993, pp. 112-122.

20. Falzon, P.J., and Herszberg, I., "Mechanical performance of 2-D braided carbon/epoxy composites," Composites Science and Technology, vol. 58, 1998, pp. 253-265. 
21. Quek, S.C., Waas, A.M., Shahwan, K.W., and Agaram, V., "Failure mechanics of triaxially braided carbon composites under combined bending-compression loading," Composites Science and Technology, vol. 66, 2006, pp. 2548-2556.

22. Quek, S.C., Waas, A., Shahwan, K.W., and Agaram, V., "Compressive response and failure of braided textile composites: Part 2-computations," International Journal of Non-Linear Mechanics, vol. 39, Jun. 2004, pp. 649-663.

23. Song, S., Waas, A.M., Shahwan, K.W., Xiao, X., and Faruque, O., "Braided textile composites under compressive loads: Modeling the response, strength and degradation," Composites Science and Technology, vol. 67, 2007, pp. 3059-3070.

24. Fang, G., and Liang, J., "A review of numerical modeling of three-dimensional braided textile composites," Journal of Composite Materials, vol. 45, Jul. 2011, pp. 2415-2436.

25. Yuan, Z., and Fish, J., "Toward realization of computational homogenization in practice," International Journal for Numerical Methods in Engineering, vol. 73, Jan. 2008, pp. 361-380.

26. Li, X., Binienda, W.K., and Littell, J.D., "Methodology for Impact Modeling of Triaxial Braided Composites Using Shell Elements," Journal of Aerospace Engineering, vol. 22, Jun. 2009, pp. 310317.

27. Blinzler, B.J., "Systematic Approach to Simulating Impact for Triaxially Braided Composites," Dissertation, University of Akron, 2012.

28. Cheng, J., and Binienda, W., "Simplified Braiding through Integration Points Model for Triaxially Braided Composites," Journal of Aerospace Engineering, vol. 21, 2008, pp. 152-161.

29. Xiao, X., Kia, H. G., and Gong, X.-J., "Strength prediction of a triaxially braided composite," Composites Part A: Applied Science and Manufacturing, vol. 42, Aug. 2011, pp. 1000-1006.

30. Littell, J., "The Experimental and Analytical Characterization of the Macromechanical Response for Triaxial Braided Composite Materials," Dissertation, University of Akron, 2008.

31. Matzenmiller, A., Lubliner, J., and Taylor, R.L., "A constitutive model for anisotropic damage in fiber-composites," Mechanics of Materials, vol. 20, 1995, pp. 125-152.

32. Bednarcyk, B.A., "Modeling woven polymer matrix composites with MAC/GMC," NASA/CR2000-210370, 2000.

33. Goldberg, R.K., Blinzler, B.J., and Binienda, W.K., "Investigation of a macromechanical approach to analyzing triaxially braided polymer composites," AIAA J., vol. 49, no. 1, 2011, pp. 205-215.

34. Littell, J., Binienda, W., Roberts, G., and Goldberg, R., "Characterization of Damage in Triaxial Braided Composites under Tensile Loading," Journal of Aerospace Engineering, vol. 22, 2009, pp. 270-279.

35. Charoenphan, S., Bank, L.C., and Plesha, M.E., "Use of LS-DYNA shell elements in the analysis of composite plates with unabalanced and unsymmetric layups," International LS-DYNA Conference, 2000, pp. 47-56. 



\begin{tabular}{|c|c|c|}
\hline \multicolumn{2}{|c|}{ REPORT DOCUMENTATION PAGE } & $\begin{array}{l}\text { Form Approved } \\
\text { OMB No. 0704-0188 }\end{array}$ \\
\hline \multicolumn{3}{|c|}{ 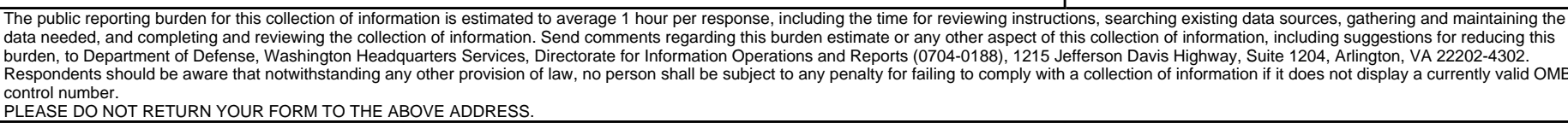 } \\
\hline $\begin{array}{l}\text { 1. REPORT DATE (DD-MM-YYYY) } \\
01-06-2013\end{array}$ & $\begin{array}{l}\text { 2. REPORT TYPE } \\
\text { Technical Memorandum }\end{array}$ & 3. DATES COVERED (From - To) \\
\hline \multirow{3}{*}{\multicolumn{2}{|c|}{$\begin{array}{l}\text { 4. TITLE AND SUBTITLE } \\
\text { Improved Subcell Model for the Prediction of Braided Composite Response }\end{array}$}} & 5a. CONTRACT NUMBER \\
\hline & & 5b. GRANT NUMBER \\
\hline & & 5c. PROGRAM ELEMENT NUMBER \\
\hline \multirow{3}{*}{\multicolumn{2}{|c|}{$\begin{array}{l}\text { 6. AUTHOR(S) } \\
\text { Cater, Christopher, R.; Xiao, Xinran; Goldberg, Robert, K.; Kohlman, Lee, W. }\end{array}$}} & 5d. PROJECT NUMBER \\
\hline & & 5e. TASK NUMBER \\
\hline & & $\begin{array}{l}\text { 5f. WORK UNIT NUMBER } \\
\text { WBS 284848.02.04.03.02.02.02 }\end{array}$ \\
\hline \multicolumn{2}{|c|}{$\begin{array}{l}\text { 7. PERFORMING ORGANIZATION NAME(S) AND ADDRESS(ES) } \\
\text { National Aeronautics and Space Administration } \\
\text { John H. Glenn Research Center at Lewis Field } \\
\text { Cleveland, Ohio 44135-3191 }\end{array}$} & $\begin{array}{l}\text { 8. PERFORMING ORGANIZATION } \\
\text { REPORT NUMBER } \\
\text { E-18674 }\end{array}$ \\
\hline \multirow{2}{*}{\multicolumn{2}{|c|}{$\begin{array}{l}\text { 9. SPONSORING/MONITORING AGENCY NAME(S) AND ADDRESS(ES) } \\
\text { National Aeronautics and Space Administration } \\
\text { Washington, DC 20546-0001 }\end{array}$}} & $\begin{array}{l}\text { 10. SPONSORING/MONITOR'S } \\
\text { ACRONYM(S) } \\
\text { NASA }\end{array}$ \\
\hline & & $\begin{array}{l}\text { 11. SPONSORING/MONITORING } \\
\text { REPORT NUMBER } \\
\text { NASA/TM-2013-217875 }\end{array}$ \\
\hline \multicolumn{3}{|c|}{$\begin{array}{l}\text { 12. DISTRIBUTION/AVAILABILITY STATEMENT } \\
\text { Unclassified-Unlimited } \\
\text { Subject Categories: } 24 \text { and } 39 \\
\text { Available electronically at http://www.sti.nasa.gov } \\
\text { This publication is available from the NASA Center for AeroSpace Information, 443-757-5802 }\end{array}$} \\
\hline
\end{tabular}

\section{SUPPLEMENTARY NOTES}

\section{ABSTRACT}

In this work, the modeling of triaxially braided composites was explored through a semi-analytical discretization. Four unique subcells, each approximated by a "mosaic" stacking of unidirectional composite plies, were modeled through the use of layered-shell elements within the explicit finite element code LS-DYNA. Two subcell discretizations were investigated: a model explicitly capturing pure matrix regions, and a novel model which absorbed pure matrix pockets into neighboring tow plies. The in-plane stiffness properties of both models, computed using bottom-up micromechanics, correlated well to experimental data. The absorbed matrix model, however, was found to best capture outof-plane flexural properties by comparing numerical simulations of the out-of-plane displacements from single-ply tension tests to experimental full field data. This strong correlation of out-of-plane characteristics supports the current modeling approach as a viable candidate for future work involving impact simulations.

\section{SUBJECT TERMS}

Polymer matrix composites; Braided composites; Finite element method

\begin{tabular}{|c|c|c|c|c|}
\hline \multicolumn{3}{|c|}{ 16. SECURITY CLASSIFICATION OF: } & \multirow{2}{*}{$\begin{array}{l}\text { 17. LIMITATION OF } \\
\text { ABSTRACT } \\
\text { UU }\end{array}$} & \multirow{2}{*}{$\begin{array}{l}\text { 18. NUMBER } \\
\text { OF } \\
\text { PAGES } \\
28\end{array}$} \\
\hline $\begin{array}{l}\text { a. REPORT } \\
\mathrm{U}\end{array}$ & $\begin{array}{l}\text { b. ABSTRACT } \\
\mathrm{U}\end{array}$ & $\begin{array}{l}\text { c. THIS } \\
\text { PAGE } \\
\text { U }\end{array}$ & & \\
\hline
\end{tabular}

\begin{tabular}{l} 
19a. NAME OF RESPONSIBLE PERSON \\
STI Help Desk (email:help@sti.nasa.gov) \\
\hline 19b. TELEPHONE NUMBER (include area code) \\
443-757-5802
\end{tabular}



